and physiological explanation. Cannot some one of ycur numerous scientific contributcrs favour us with one?

It is this : Take a slip of thin card about three inct.es long and one wide. Bend up the two end inches at right angles. Perforate one of these vertical ends with a pin-hole, and the other directly and concentrically opposite with a square hole

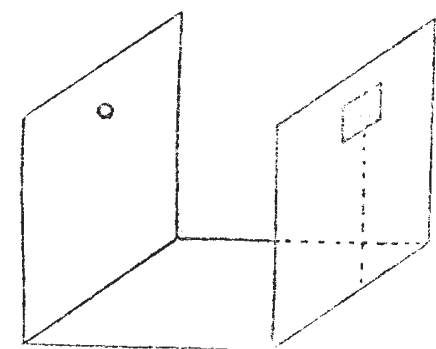

Observe.-The pin may be placed horizontally, or in any position, with the same result.

about one-eighth of an inch square. Place a small pin in this end, so that the head may be nearly in the middle of the square hole. Now apply this end to your eye and look through both holes at the sky, and you will see the pin apparently beyond the round hole and reversed in position! WILLIAM WILSON

Eirene, Chester, May 4

[This very pretty experiment seems novel. The explanation is, of course, exce sively simple. What is seen is the shadow of the pin, thrown on the retina by the light diverging from the small hole. As the shadow is erect on the retina, it produces vision of an inverted pin. This appears to be situated about the dis tance of most distinct vision (ten inches or so), and therefore behind the hole.-ED.]

Laurence IIARgrave, Sydney, should refer to the letter of the Rev. R. Abbay on the "Rayons de Crépuccule" in vol. xviii. p. 329 , and the articles and correspondence therein referred to.

\section{SCIENCE IN CHINA}

II.

$\mathrm{T}$ is a generally received opinion that the Chinese language presents extraordinary difficulties, both in its acquisition by Europeans and in its use for the expression of the more exalted ideas of Western learning. The attempt to translate modern scientific or technical books into a language so ancient, so crude, and so unchanging is regarded by many who have not given careful attention to the matter as almost absurd. It is readily granted by them that such subjects as the doctrines of Christianity or affairs of a political nature might be expressed easily in the language of a people among whom religion and diplomacy have for ages been carried to a considerable state of advancement. Eut from the almost total absence of native scientific literature and pursuits there is necessarily a paucity of scientific terms, and this appears at first sight to form an almost impassable barrier to the use of Chinese for scientific purposes. A little investigation however will show that this opinion is without foundation; and that from the time the early Jesuit missionaries commenced their compilations up to the present day no serious difficulties have been experienced by foreign translators.

The question of nomenclature, however, is one that naturally has to be met at the outset. If it were necessary to use only such terms as are to be found in standard Chinese dictionaries, or if it were forbidden to give any new shades of meaning to existing characters the task of translation could never be accomplished. But it must be borne in mind that the Chinese, like other languages, is capable of growth. The increasing intercourse of China

\footnotetext{
I By Mr. John Fryer, Chief. Translator to the Chinese Arsenal. Continued
from p. Ir.
}

with Western nations is undoubtedly making vast additions to the number of words in current use. The Emperor, it is true, has the power of deciding the exact manner in which characters are to be written, and in various instances certain characters have been forbidden to be written in certain ways; but he is powerless to check the changes and additions that are now fast taking place in the language all over the Empire. Where it has become necessary to express a new idea, or to give a name to a new object in Chinese, there has always been found a way of managing the matter more or less satisfactorily; and hence some very clumsy specimens of nomenclature are gradually becoming current, especially among such natives as have much intercourse with foreigners. Of course all such new terms have to stand or fall on their own merits, and if radically wrong or misleading they are pretty certain eventually to be supplanted by better ones. This is merely what naturally happens in the growth of all languages, and although many inconveniences necessarily occur when terms have to be changed, yet there seems to be no help for it. It will be remembered that when the English language began to borrow largely from Greek and Latin, many scientific and technical terms were coined which have since fallen into disuse or been supplanted by others. So it must necessarily be in Chinese with regard to the words borrowed from the English or other languages.

It ought, however, to be possible for the pioneers of modern sciences and arts in China, by exercising great care and by working in harmony, to establish such a system of nomenclature that no very extensive alterations need be made in future years. A Chinaman of ordinary intelligence ought to be able to take up the translation of a work on such a subject as chemistry, for instance, and understand the nomenclature quite as well as a European of similar capacity, and, knowing nothing of chemistry, would understand the original when placed in his hands for the first time. Every new term being explained or defined only when first used, it would of course be useless for an ordinary Chinaman to begin in the middle of such a work and expect to understand everything he read. And yet not only Chinese but foreigners have been known to treat the translations published at the Arsenal in this way. Finding the nomenclature unintelligible to themselves or their Chinese friends, or their teachers or writers, they have condemned all such attempts to express the higher branches of Western learning in Chinese as useless, and have come to the conclusion that the study of European languages is the only way in which satisfactory progress will ever be made in China.

Before commencing the work of the Translation Department it was seen to be necessary to establish a system by which the nomenclature to be employed should be determined. After considerable discussion the following plan was agreed upon by those who organised the department :-

I. Existing Nomenclature.-Where it is probable a term exists in Chinese, though not to be found in dictionaries-

$a$. To search in the principal native works on the arts and sciences, as well as those by the Jesuit missionaries and recent Protestant missionaries;

$b$. To inquire of such Chinese merchants, manufacturers, mechanics, \&c., \&c., as would be likely to have the term in current use.

2. Coining of New Terms.-Where it becomes necessary to invent a new term, there is a choice of three methods :-

a. Make a new character, the sound of which can easily be known from the phonetic portion, or use an existing but uncommon character giving it a new meaning.

b. Invent a descriptive term, using as few characters as possible.

c. Phoneticise the foreign term, using the sounds of the 
Mandarin dialect, and always endeavouring to employ the same character for the same sound as far as possible, giving preference to characters most $u^{3}$ ed by previous translators or compilers.

All such inventec terms to be regarded merely as provisional and to be discarded if previously existing ones are discovered or better ones can be obtained before the works are published.

3. Construction of a General Vocabulary of Terms and List of Proper Names.-During the translation of every book it is necessary that a list of all unusual terms or proper names employed should be carefully kept. These various lists should be gradually collected and formed into a complete volume for general use, as well as with a view to publication.

Unfortunately the above plan has not been thoroughly or consistently carried out, and hence there exists a certain amount of confusion in the works of the different translators already published, and which can only be partially rectified in future editions. This is greatly to be regretted, because the labour that would have been involved would have been trifling compared with the great advantages to be derived. It is to be hoped that the Chinese as well as the foreign members of the department will in time appreciate the necessity of using the same terms invariably throughout the whole series of publications. It is manifest that the practical utility of each one's work depends greatly upon the extent to which the above rules have been observed.

Next to nomenclature it may be well to consider the selection and arrangement of the various works compiled or translated at the Kiangnan Arsenal. The original idea was, as before stated, to prepare an encyclopæedia that should bear some resemblance to the "Encyclopædia Britannica." Jt was soon found, however, that many of the treatises in the eighth edition of that valuable work were too elementary and too far behind the time. It became necessary, therefore, to translate from more modern and complete publications. Various high officials asked to have books translated for them on special subjects. Several treatises not considered sufficiently complete had to be supplemented by larger ones, and hence the idea of an encyclopæedia has gradually been almost lost; while a miscellaneous collection of translations and compilations has been the result, and the range of subjects is comparatively limited. In most cases each translator or Chinese writer seems merely to have selected such subjects as suited him bes', without regard to the symmetry or harmony of the entire collection. There are thus several important subjects, such as natural history, biography, \&c., not yet noticed, while there are various treatises on others of comparatively little importance. As might be expected, military and naval science is one of the subjects that has received a large share of attention.

The general defect about most of the publications is that they are far too elaborate and profound, and consequently can only be understood by a few, while the masses can never master them. It was to remedy this defect that the Chinese Scientific Magazine was commenced, although it has no direct connection with this department. Recently some of the English "Science Primers" have been translated by Dr. Allen, and will no doubt help to supply the want. The "School and Textbook Series," however, will probably be the chief means by which a lower and an intermediate grade of books on scientific subjects will be furnished; and although the series owes its origin to the Missionary Conference held in Shanghai in 1877 , it has the two European members of the Translation Departmerit on its managing committee. To some extent this series, when completed, will therefore be supplementary to the publications from the Kiangnan Arsenal, and it is arranged that a part, at least, of the series shall be printed at that place.
Next as to the manner in which the work of translation or compilation is carried on. The foreign translator, having first mastered his subject, sits down with the Chinese writer and dictates to him sentence by sentence, consulting with him whenever a difficulty arises as to the way the ideas ought to be expressed in Chi.rese, or explaining to him any point that happens to be beyond his comprehension. The manuscript is then revised by the Chinese writer, and any errors in style, \&c., are corrected by him. In a few cases the translations have been carefully gone over again with the foreign translator, but in most instances such an amount of trouble has been avoided by the native writers, who, as a rule, are able to detect errors of any imporiance themselves, and who, it must be acknowledged, take great pains to make the style as clear and the information as accurate as possible. A fair copy having been made, the work is placed in the hands of the foreman of the printing department, who causes it to be written out on sheets of thin transparent paper in the large bold book-characters of the "Sung" pattern, and pasted on blocks ready for the engraver. All illustrations, diagrams, \&c., are drawn on the same paper by an experienced draughtsman, and cut at the same time and on the same kind of blocks as the characters with which they are interspersed, as in foreign books. In case of steel engravings, such as those accompanying the last edition of Herschel" " Outlines of Astronomy," translated by Mr. Wylie, the illustrations have been printed in England from the original plates. The various charts have been printed from copper plates engraved at the Arsenal.

It may seem strange that with such facilities for printing in Chinese by metal type as exist in Shanghai, and with a complete fount of such type as well as a good cylinder press on the premises, these books are nevertheless cut on wooden blocks and printed by hand, in the old fashioned way that existed in China for so many ages before printing was known in Europe. The fact is, however, that as a matter of economy and convenience the old system is preferable. The blocks are all of the same size, about eight inches by twelve inches, and about half an inch thick. Each block represents two leaves or four pages of the book, being engraved on both sides. The blocks for a complete work can thus be stowed away in a very small compass. The cost of engraving a page of these wooden blocks is said to be but little more than the expense of setting up a page of Chinese type and preparing it for the press. An edition of one copy can be printed if no more are required, and thus the expense of keeping a large stock of printed books on hand, some of which might eventually have to be sold as waste paper when they grew out of date or revisions had to be made, as is the case among ourselves, is entirely avoided. Any errors or misprints that may be discovered can as a rule be corrected on the blocks with but very little trouble. A skilful printer can print by hand five thousand leaves of two pages each in a day, using no press or machinery whatever. He supplies his own tools and receives as wages about twenty-five dollar cents. a day. The paper ordinarily used is white and of the best quality, although a yellowish kind is also made use of at a reduction of 20 per cent. on the selling price. The books are bound in the usual Chinese style and fastened with white silk thread. They present an appearance which satisfies the taste of the most fastidious native.

To those who regard the Chinese language as incapable of expressing modern Western learning, and who consider European languages to be the only medium by means of which the Chinese can become proficient in the Arts and Sciences, the establishment of the Translation Department necessarily appears to be a useless waste of time and money. To those again who grant the possibility of carrying on the work, but suppose that English is destined to become the universal language at $\mathrm{n} n$ very distant 
period, or even before the close of the present century, this attempt to supply Chinese Iiterature with the results of modern discoveries in science and art must of course appear to be conferring a mere transient advantage.

But it is no difficult matter to see that the translation and publication of books in Chinese as it is carried on at the Kiangnan Arsenal and other places is the great means by which the intellectual stagnation of China is to be broken up. This work must necessarily go on and increase rapidly now that a current of thought has begun to set in. As long as foreigners have any knowledge to impart that is of real advantage to the Chinese, so long will the Chinese make efforts to obtain it; for the more the celestial mind drinks at this fountain the greater will become its thirst for further supplies.

The fact that this Translation Department has been established and kept up so long by the Government argues well for the future prospects of China, as it shows that whatever may be the national pride in her antiquated literature, or whatever may be her attitude towards the diplomatists of foreign powers, or the missionaries of foreign religions, she recognises the fact that knowledge is confined to no nation or country. She is therefore willing to be taught even by the "foreign barbarians" such useful things as she feels she is ignorant of. But she must do this of her own accord and in her own way, or not at all. It is a matter in which she is not to be dictated to, as in the case of treaties or missionary rights. She has freely availed herself of what she has considered beneficial, and has not been sparing in funds to enable knowledge to be disseminated throughout the Empire. This willingness to be taught and to pay for being taught $i$; one of the most hopeful features that has occurred in her intercourse with foreign countries, and is deserving of the highest commendation.

The work at the Translation Department is at present only in its infancy; but enough has been done to establish a foundation upon which a large and important structure will eventually arise. Having been commenced and carried on only in obedience to a natural and instinctive desire for knowledge, it ought to go on harmoniously with the course of events, and prove a powerful lever in the regeneration of China. The large number of copies of works already sold at cost price without any attempt to bring them before the public notice evinces the appreciation of the masses of the people; for a Chinaman is very slow in parting with his dollars for what he does not value or admire, or derive benefit from in some way or other. It would be strange if the knowledge that has only been acquired by such vast expenditure of thought and labour by Western nations did not make its value felt among the Chinese; for by means of these books they can in some things place themselves on a level with foreigners without going through the difficulties attending discoverers and inventors.

It is gratifying to find that some of these translations have already found their way as text-books in the Peking University and in higher kinds of mission schools. For example, the work on Trigonometry has been used to advantage in Mr. Mateer's school at Tangchow, in the shantung province.

Another cheering feature in connection with the Translation Department is, that it is not the only undertaking of the kind in China. Even before it had fairly commenced, Dr. Martin, the learned president of the Peking University, had begun to publish works on natural science and international law. Both he and his fellow-helpers have since published various works on scientific and diplomatic subjects, which have become very popular and have proved of great utility to the Government. Their translations are of a high standard, and are conducted in a style which renders them acceptable to literary men and officials of the highest grade. It is to be regretted that no detailed account of this important work that has been carried on in Peking for so many years appears to have yet been given to the public. Various other Protestant missionaries have done a great service to the country by their long list of published translations in Chinese. The names of at least half a dozen of them will be handed down to future generations as the foremost pioneers of the spread of Western arts and sciences in the "Flowery Land."

The establishment of Chinese legations at the courts of all the great treaty powers, and the creation of Chinese professorships at the Oxford, London, Paris, and Harvard Universities, are events which show the increasing importance of the study of the Chinese language. It is therefore not in vain to hope that in foreign countries, as well as in China, the work of supplying useful knowledge to the Chinese by means of their own language will eventually be carried on to an extent which may bear some reasonable proportion to the size and needs of the "Middle kingdom."

One of the latest and most promising of the schemes which have a similar object in view to the Translation Department is that previously alluded to, namely, the stpplying a series of text-books chiefly for use in mission schools, but still of a character suitable to the wants of the nation at large. The practical working of this scheme was placed in the hands of a committee of six gentlemen, all of whom have already had considerable experience in this kind of labour. A series of fifty-five works has been determined on, which embraces several books of an elementary kind that will, no doubt, do well as introductions to the more elaborate treatises on similar subjects already in existence.

It is, however, to the future that we must look for the chief part of the practical utility of all this translation work. Such a vast nation as the Chinese is not to be started into motion and made to follow in the wake of Western civilisation all at once. Generation after generation will have to come and go before the complete transformation will be effected, and the intellectual as well as the physical resources of the country will be turned to the best account. Hereditary tendencies in a wrong direction are not to be eradicated without a long series of struggles. The system of ignoring everything but the "Four Books" and the "Five Classics" at the Government examinations, which are the passports to the highest offices in the State, is not destined to last for ever. By patiently working on even the present generation of foreigners engaged in this laborious task of spreading intellectuai light may hope to see much good resulting from their efforts. If they do not live to see Western learning occupying the position it ought to do in Government examinations they may yet see it holding a prominent place.

The work of translating and compiling scientific books is for the time being perhaps about as dull and unthankful a task as any foreigner could engage in, especially in such a secluded place as the Kiangnan Arsenal, and under the depressing influences of the climate of this part of China. Nothing but a strong sense of duty and a firm belief that this kind of labour is one of the most effective means, under the Divine guidance, for bringing about the intellectual and moral regeneration of this great country, has sufficed to render endurable the long and weary years and weary hours of close and continuous application which it has involved.

4. List of Books and Statistics.-The Translation Department, although established in the year I 868 , did not commence the publication of books till the year $187 \mathrm{r}$, when a treatise on Practical Geometry and another on Coal and Coal Mining made their appearance. Up to the present year the number of works published amounts to ninety-eight. These works are contained in 236 volumes, a Chinese volume generally consisting of 120 to 200 pages and representing perhaps on an average about 
the same number of pages of an ordinary English work in octavo, with small pica type. Of course the style of the original as well as the style of translation may be such as to render this approximate number rather wide of the mark.

The number of copies of works sold up to the end of June, 1879, amounts to $3 \mathrm{I}, \mathrm{III}$, representing 83,454 volumes. The number of maps and charts published amounts to twenty. seven sheets. Most of them are adaptations of the charts of the British Admiralty, and were printed from copper plates engraved at the Kiangnan Arsenal. The number already sold is 4,774 sheets.

The sum realised by the sale of books and charts may be estimated at about 17,500 dollars, or roughly $3,500 \mathrm{l}$.

The numbers sold up to the present time, though considerable, are nothing compared with what might have been expected among such an extensive population. But with no regular means of communication, no postal or railway arrangements, no agencies, and no advertisements or other means of bringing them into general notice or distributing them, it is easy to understand why more have not already been disposed of.

The various periodicals, such as summaries of foreign news, political essays, \&c., are not reckoned in the above numbers. From three to five hundred copies of these books are published and distributed gratuitously to various officials both in the vicinity of Shanghai and in distant provinces.

Forty-four works, representing about 142 volumes, have been translated, and are in various stages of preparation, but the publication is not yet commenced.

Thirteen works which are now in the course of transla tion and of which thirty-one volumes are already completed.

Forty-three books are to be published by the Committee of the "School and Text-book Series." Most of these works are nearly ready to be placed in the printer's hands.

Various treatises on scientific subjects have been published by Protestant missionaries; but about them it has been impossible to obtain statistics as to the numbers printed and sold.

The following list will give some idea of the number and class of scientific works that have been translated:-

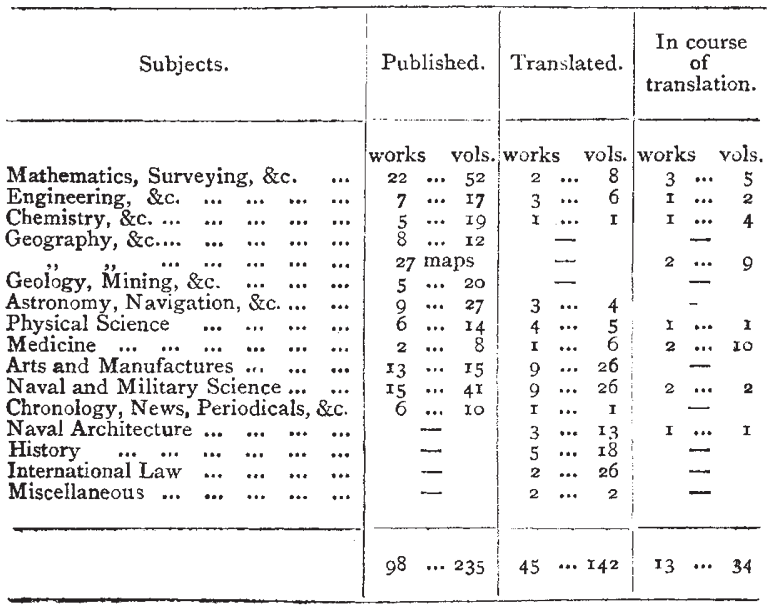

\section{THE WILLUGHBY SOCIETY ${ }^{1}$}

$\mathrm{T} \mathrm{T}$ was a happy thought to found an association under 1 the name of Francis Willughby, having for its object the reprinting of scarce ornithological works, thus keeping the name of the writer of "Ornithologiæ Libri Tres" in remembrance and doing a service to the working ornitho-

IDesfontaines's "Mémoire sur quelques Nouvelles Espèces d' Oiseaux des Côtes de Barbarie" ( $\mathrm{r}^{8} 7$ ). II. "Ornithological Papers," by Sir Andrew Smith $(1830-34)$. logist. It is nearly nine years over two centuries since Willughby died (July 3, I672). About seven years younger than John Ray, he studied at Trinity College, Cambridge, under Ray; but though at first the pupil, he was soon the friend and afterwards the patron of our great English botanist. Belonging to a family of wealth and influence, Willughby soon married (1668), and settled at Middleton Hall, Warwickshire. How hard he must have worked the materials for his great work left at the time of his untimely death amply prove. His second son (the elder died) was created a peer by Queen Anne (Viscount Middleton). An annuity was left to Ray, who edited "The Ornithology," which was printed in London (1676) at the expense of Willughby's widow. Willughby has been called the "father of systematic zoology in this country." The new Willughby Society seems determined to follow in his footsteps.

The reprint in fac-simile of M. Desfontaines's " Mémoire" will be no doubt welcomed by the members, and it is only by members that these reprints can be obtained. Honoured by botanists in the beautiful genus Desfontainea, this account of the birds met by him at Barbary is very rare; and we agree with Prof. Newton that few papers are less accessible to ornithologists than those published by the late Sir A. Smith in the South African Quarterly Fournal. We trust the Willughby Society will meet with the support it deserves from the members of $I b i$ and from bird-lovers in general.

\section{ZOOLOGY OF THE DUTCH ARCTIC EXPEDITION ${ }^{1}$}

A SUPPLEMENTARY number of the Niederländisches Archiv für Zoologie just issued is composed of an instalment of five papers describing certain of the animals collected or dredged during the two Arctic voyages of the schooner William Barents, together with a list of all the places dredged at, and a map with these and the track marked on it. The ship visited the north of Spitzbergen and the west coast of Novaia Zemlia, and stretched northwards thence almost to Franz-Josef Land. All the dredgings, except two off the north coast of Spitzbergen, were made in the Barents Sea, between Novaia Zemlia and the north of Norway and Bear Island. Dr. R. Horst reports on the Annelids. He found no new species amongst the fifty-one obtained in the Barents Sea. Hjalmar Theel found in the Kara Sea, on the east side of Novaia Zemlia, ninety species. There can be little doubt that the fauna of the two seas, which join in several places, must be nearly identical, yet amongst the thirty-one species from the Barents Sea are fourteen not yet collected in the Kara Sea. The Annelid collection seems to have been rather a meagre one, and must not be taken as representative. The Pycnogonids are described by Dr. P. P. C. Hoek. Examples of these were obtained on fourteen out of the entire thirty dredgings made. They are of eight species, one of which is new. Amongst them is one species of the genus Colossendeis, numerous forms of which were obtained by the Challenger in southern latitudes, some attaining there gigantic proportions. The Lamellibranchiata are described by Dr. van Haren Noman, who appends to his paper an important memoir, illustrated by three plates, on the anatomy of the eyes, gills, and other parts of Pecten Granlandicus and other forms; Dr. A. A. W. Hubrecht contributes a list of the fishes; and Dr. F. A. Jentink a few notes on the field-mouse of Novaia Zemlia, Curriculus torquatus, which, unlike all of its allies, turns white in winter. The animal ranges over the whole of Arctic America, Europe, and Asia, and in late geological periods extended as far south as England, Germany, and the basin of the Loire.

I "Zoological Results of the two William Barents Arctic Expeditions in I8 78 and $1879 . "$ 